\title{
Computational investigation of the histidine ammonia-lyase reaction: a modified loop conformation and the role of the zinc(II) ion
}

Received: 27.05.2010 / Accepted: 02.09.2010

Amalia-Laura Seff ${ }^{1}$, Sarolta Pilbák $^{2}$, Ioan Silaghi-Dumitrescu ${ }^{1}$, and László Poppe ${ }^{2, 凶}$

${ }^{1}$ Faculty of Chemistry and Chemical Engineering, Babes-Bolyai University, Cluj-Napoca 400028 Romania

${ }^{2}$ Department of Organic Chemistry and Technology and Research Group for Alkaloid Chemistry, Budapest University of Technology and Economics, Budapest 1111, Hungary

${ }^{\circledR}$ Tel: +36 1463 2229; Fax: +36 1463 3297; Email: poppe@mail.bme.hu

\begin{abstract}
The possible reaction intermediates of the histidine ammonia-lyase (HAL) reaction were investigated within a tightly closed active site of HAL from Pseudomonas putida (PpHAL). The closed structure of $P p \mathrm{HAL}$ derived from the crystal structure of $P p \mathrm{HAL}$ inhibited with Lcysteine, in which the 39-80 loop including the catalytically essential Tyr53 was replaced. This modified loop with a closed conformation was modeled using the structure of phenylalanine ammonia-lyase from Anabaena variabilis (AvPAL) with a tightly closed active site as a template. In this active site of HAL, three hypothetical structures of the covalently bound intermediate were investigated by conformational analysis. The distances between the acidic pro-S $\beta$-hydrogen of the ligand and the appropriate oxygen atoms of Tyr53, Ty 280 and Glu414 - which may act as enzymic bases - in the conformations of the three hypothetical intermediate structures were analyzed together with the substrate and product arrangements. The calculations indicated that the plausible pathway of the HAL reaction involved the $N$-MIO intermediate structure in which the L-histidine substrate was covalently bound to the apoenzyme via the amino group. Density functional theory (DFT) calculations - on a truncated model of the $N$-MIO intermediate containing a $\mathrm{Zn}^{2+}$ ion coordinated to the imidazole ring of the ligand and to His83, Met382 and a water molecule - indicated the role of a $\mathrm{Zn}$-complex formation in the reactivity and substrate specificity of HAL.
\end{abstract}


Keywords Histidine ammonia-lyase - Loop conformation ' Homology model • Conformational analysis $\cdot$ DFT calculation $\cdot \mathrm{Zn}^{2+}$ ion
Abbreviations
$1 \mathrm{GKM}_{\text {mod }}$
Partially modified structure (in the 39-80 loop) of the L-cysteine inhibited histidine ammonia-lyase (PDB code: 1GKM)
B3LYP
Becke's three parameter hybrid functional combined with the Lee- Yang-Parr correlation functional
CS
Systematic conformational search
DFT
Density functional theory
FC
Friedel-Crafts type mechanism
HAL
Histidine ammonia-lyase
MIO
3,5-Dihydro-5-methylidene-4H-imidazol-4-one
MM
Molecular mechanics force field
$N$-MIO
Covalent intermediate of the HAL reaction bound to MIO via the amino group of L-histidine
PAL Phenylalanine ammonia-lyase
PAM Phenylalanine-2,3-aminomutase
PDB
Brookhaven Protein Data Bank
TAL
Tyrosine ammonia-lyase
TAM
Tyrosine-2,3-aminomutase
QM
Quantum mechanics 


\section{Introduction}

The degradation of histidine to glutamate follows a different pathway than that of other amino acids catalyzed by transaminases [1] In the first stage, histidine ammonia-lyase (HAL, EC 4.3.1.3), eliminates the $\alpha$-amino group from L-histidine (L-His) resulting the $\alpha, \beta$-unsaturated $(E)$-urocanate (Fig. 1). The $(E)$-urocanic acid is a component of human sweat and has been suggested to act as a sun blocker in human skin [2]. The absence of HAL in humans is known as a disease called histidinemia [3].

$<$ Figure 1>

HAL is a subset of the ammonia-lyase family together with the phenylalanine ammonia-lyase (PAL, EC 4.3.1.24) and tyrosine ammonia-lyase (TAL, EC 4.3.1.23) catalyzing the deamination of the corresponding L-amino acid to $(E)$-cinnamic acid and $(E)$-coumaric acid [1]. Cloning and sequencing of Pseudomonas putida genes that code HAL (hutH) and urocanase (hutU) have been described [4, 5]. HAL is also present in mammals (rat and human) [6-8]. An extensive analysis of the taxonomic distribution and phylogeny of PAL/TAL/HAL revealed that eukaryotic HAL, fungi PAL and land plants PAL have distinct origins [9]. Taxonomic distribution of HAL and PAL orthologues indicated that the ancestor of eukaryotes harbored a HAL while a PAL was introduced by horizontal gene transfer in the ancestor of fungi and the ancestor of land plants [9]. Histidine ammonia-lyase from Pseudomonas putida [10] was found to have 44, 43, 33, 32 and 31\% amino acid sequence identity to Rattus norvegicus HAL [11], to Bacillus subtilis HAL [12], to Anabaena variabilis (bacterial) PAL [13], to Rhodosporidium toruloides (yeast) PAL [14] and to Petroselinum crispum (parsley) PAL [15], respectively.

The non-oxidative deamination of the substrates, catalyzed by HAL, PAL and TAL requires the presence of 3,5-dihydro-5-methylidene-4H-imidazol-4-one (MIO) electrophilic prosthetic group [16-18] in the enzyme. As a crystal structure study of three mutants (D145A, F329G and F329A) of HAL from Pseudomonas putida (PpHAL) indicated [19], MIO is formed autocatalytically by cyclization and dehydration of an Ala-Ser-Gly tripeptide (Fig. 2) [16, 19, 20]. The MIO prosthetic group was later identified in the crystal structures of yeast [14, 21], plant [15] and bacterial PAL [22] and bacterial TAL [23]. MIO was identified in Lphenylalanine and L-tyrosine-2,3-aminomutases (PAM [24-26] and TAM [27, 28], respectively) as well. 
$<$ Figure 2>

Histidine, phenylalanine and tyrosine ammonia-lyases should remove the non-acidic pro-S $\beta$ proton from their substrates, without extracting the more acidic protons from the ammonium moiety of the corresponding L-amino acid [1]. Biochemical data were interpreted by means of two significantly different mechanisms (Fig. 1) [1]. The first proposals for the mechanism of the ammonia elimination catalyzed by HAL [29] and PAL [30] suggested that an interaction between the amino group of the substrate and the electrophilic prosthetic group of the enzyme (i.e. an $N$-MIO intermediate) facilitates the reaction owing to the formation of a better leaving group [30, 31]. Due to the difficulty entailed by this possible mechanism to abstract the nonacidic pro-S $\beta$-proton by the enzymic base in the course of ammonia elimination, an alternative mechanism involving a Friedel-Crafts (FC) type attack at the aromatic ring of the substrates by the electrophilic prosthetic group has been suggested [32]. In spite of the significant differences in the properties of these enzymes, the presence of their similar electrophilic prosthetic group seemed to indicate that HAL, PAL and TAL catalyze their reactions by analogous mechanisms [1].

After elucidation of the structure of HAL by X-ray crystallography and discovery of MIO (Fig. 2) [16], the importance of several amino acid residues at the active center (Tyr53, His83, Asn195, Gln277, Tyr280, Arg283, Phe329 and Glu414) for catalysis and substrate binding was evaluated by site-directed mutagenesis [33]. Mutagenesis was also performed for active site amino acid residues of PAL [34] that were identical or similar to the active site residues of HAL. The almost total loss of activity observed with the mutant Y53F of HAL (2650 times less active than the wild-type HAL) and with the mutant Y110F of PAL (75000 times less active than the wild-type PAL) demonstrated that Tyr53 in HAL and Tyr110 in PAL were essential for the catalysis $[33,34]$.

A unique feature of the reaction catalyzed by HAL is the significant enhancement of the

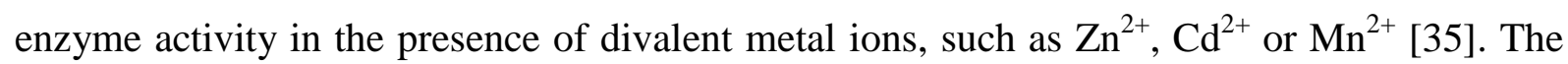
optimal activity of HAL was shown to be dependent on the addition of metal ions $[35,36]$. Based on these experimental data, it was already proposed that the interaction of the substrate with the His83 imidazole group could be mediated by coordination with $\mathrm{Zn}^{2+}$ [33].

Although mutagenesis data [33] and six crystal structures [16, 19 37] are available for HAL, the nature of the covalent reaction intermediate (Fig. 1) and the role of $\mathrm{Zn}^{2+}$ ion in the 
catalysis have not been explored or investigated by systematic computations. It has been demonstrated already - in the case of the partially modified parsley phenylalanine ammonialyase (PcPAL) - that homology modeling, systematic conformational search and ligand docking can be applied for mechanistic studies for an ammonia-lyase [34, 38, 39]. Based on the above data and methods, our goal in this study is to explore the structure of the covalent intermediate and the role of $\mathrm{Zn}^{2+}$ in the HAL reaction by using partial homology modeling, systematic conformational search and DFT calculations.

\section{Theory and methods}

\section{Experimental ammonia-lyase structures used for the computations}

Six crystal structures of Pseudomonas putida histidine ammonia-lyase HAL (Brookhaven Protein Data Bank (PDB) codes: 1B8F, unliganded PpHAL $\mathrm{H}_{\text {Cys273Ala-mut }}[16]$; 1EB4,

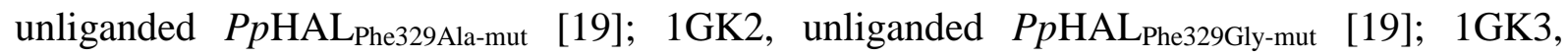
unliganded $P p \mathrm{HAL}_{\text {Asp145Ala-mut }}$ [19]; 1GKJ, unliganded $P p \mathrm{HAL}_{\text {Tyr280Phe-mut }}$ [37]; 1GKM, $P p H A L$ inhibited with L-cysteine [37]) were compared. The six HAL structures showed only small differences in the positions of the amino acid side chains within the active center, with the exception of the arrangement of Met382 in the PpHAL inhibited with L-cysteine (1GKM).

\section{Modeling the Tyr53-containing 39-80 loop region of PpHAL structure}

A HAL structure with a closed active site $\left(1 \mathrm{GKM}_{\text {mod }}\right)$ was constructed by modifying the PpHAL structure which included L-cysteine inhibitor (PDB code: 1GKM) by the replacement of the 39-80 loop, containing the catalytically essential Tyr53, in every subunit of the homotetrameric enzyme. The crystal structure of Anabaena variabilis phenylalanine ammonia-lyase PAL (PDB code: 3CZO) with a tightly closed active site [13] has been used as a template for modeling the closed conformation of the 39-80 loop of PpHAL. For homology modeling, the SwissPDB Viewer [40-42] program suite and the Swiss-Model automated homology modeling service [43-46] were used. 
Construction of the covalently bound MIO-substrate intermediate models in the 1GKM $_{\text {mod }}$ structure

The L-cysteine inhibitor (Cys1510) within the modified structure of PpHAL (1GKM mod $)$ was replaced by L-histidine. A portion of the $\mathrm{GKM}_{\text {mod }}$ structure (overlapping spheres of $15 \AA$ radius around the $\mathrm{C}_{1}$ of the ligand and $12 \AA$ radius around the $\mathrm{O}$ atom of the W544 water, consisting of 149 amino acid residues) was used as the active site model of PpHAL for CS calculations. Three initial ligand structures [an $N$-MIO model and two diastereomeric $(S, S)$ FC and $(R, S)$-FC models] were built for the systematic conformational analysis search (CS) from this L-histidine by turning its carboxyl group towards $\operatorname{Arg} 283$ and its imidazole ring close to the HAL-specific His83 residue and constructing the appropriate bonds between the methylene carbon of $\mathrm{MIO}$ and the nitrogen atom of amino group or the $\mathrm{C}_{4}$ atom of imidazole of the ligand. Then, hydrogens were added to the model portion of the $1 \mathrm{GKM}_{\text {mod }}$ structures and the $C$ - and $N$-termini at cuts were transformed into neutral aldehyde and amino moieties by HyperChem [47] standard procedure. The resulted structures were verified and corrected using Molfunction [48].

Conformational analysis for the covalently bound MIO-substrate intermediates within the partial 1GKM $_{\text {mod }}$ structure

Two separate CSs were performed for each covalently bound reaction intermediate [ $N$-MIO, $(S, S)$-FC and $(R, S)$-FC models] bearing a proton on either the $\pi$ or the $\tau$ nitrogen of the imidazole ring ( $N_{\pi \mathrm{H}}$ and $N_{\tau \mathrm{H}}$ series of conformers). The six CS calculations involving the ligand and MIO [28 atoms in the $N$-MIO model and 29 atoms in the $(S, S)$-FC / $(R, S)$-FC) models] were performed in a rigid enzymic environment without water molecules. For the $N-$ MIO model, three torsions [along the axes of $\mathrm{C}_{(\mathrm{MIO}-\mathrm{C} 5)}-\mathrm{C}_{(\mathrm{MIO}-\mathrm{CH} 2)}, \mathrm{C}_{(\mathrm{MIO}-\mathrm{CH} 2)}-\mathrm{N}_{(\mathrm{HisL})}$, $\left.\mathrm{N}_{(\mathrm{HisL})}-\mathrm{C}_{(\mathrm{HisL}-\mathrm{C} \alpha)}\right]$, and for the $(S, S)$-FC and $(R, S)$-FC models four torsions [along the axes of $\mathrm{C}_{(\mathrm{MIO}-\mathrm{C} 5)}-\mathrm{C}_{(\mathrm{MIO}-\mathrm{CH} 2)}, \mathrm{C}_{(\mathrm{MIO}-\mathrm{CH} 2)}-\mathrm{C}_{(\mathrm{HisL}-\mathrm{C} 4)}, \mathrm{C}_{(\mathrm{HisL}-\mathrm{C} 5)}-\mathrm{C}_{(\mathrm{HisL}-\mathrm{C} \beta)}$ and $\left.\mathrm{C}_{(\mathrm{HisL}-\mathrm{C} \beta)}-\mathrm{C}_{(\text {HisL-C } \alpha)}\right]$ were varied during the CSs. The CSs were performed by the HyperChem implemented CS module [47] using the default settings $\left(\mathrm{MM}+\right.$ forcefield; gradient: $0.1 \mathrm{kcal} \mathrm{mol}^{-1}$; Polak-Ribiere method; limits: 300 iterations, 150 optimizations, 15 conformations; test options: "skip if atoms are closer than $\left.0.3 \AA^{\prime \prime}\right)$. 


\section{Geometry optimization of the covalent intermediates, L-histidine and $(E)$-urocanate within the active site of $\mathrm{HAL}$}

L-Histidine and (E)-urocanate structures were built, by proper rearrangement of bonds (Fig. 3 ), from those conformers of the covalent intermediates which had straight main-chain conformation $\left[N-\mathrm{MIO}\right.$ series $\left(N_{\tau \mathrm{H}}: \mathrm{c} 1-\mathrm{c} 3, \mathrm{c} 5, \mathrm{c} 8, \mathrm{c} 9, \mathrm{c} 11 ; N_{\pi \mathrm{H}}: \mathrm{c} 1-\mathrm{c} 4, \mathrm{c} 6, \mathrm{c} 9, \mathrm{c} 10\right) ;(R, S)-\mathrm{FC}$ series $\left(N_{\tau \mathrm{H}}: \mathrm{c} 2, \mathrm{c} 4, \mathrm{c} 5, \mathrm{c} 7-\mathrm{c} 9 ; N_{\pi \mathrm{H}}: \mathrm{c} 2\right)$ and $(S, S)$-FC series $\left.\left(N_{\tau \mathrm{H}}: \mathrm{c} 1-\mathrm{c} 2 ; N_{\pi \mathrm{H}}: \mathrm{c} 2\right)\right]$. In all substrate, intermediate and product structures, the ligand together with MIO (substrate, intermediate) or $\mathrm{NH}_{2}-\mathrm{MIO}$ (product) and the His83, Tyr280, Tyr53, Asn195, Gln277, Glu414, Arg283 and Phe329 (a total of 116 atoms) were optimized in a $15 \AA$ spherical part (2221 atoms) of the $1 \mathrm{GKM}_{\text {mod }}$ structure, while keeping the residual part rigid. The optimizations were performed by the HyperChem [47] implemented MM+ forcefield with the default settings (gradient: $0.1 \mathrm{kcal} \mathrm{mol}^{-1}$; Polak-Ribiere method).

$<$ Figure 3>

\section{Docking L-histidine and $(E)$-urocanate into the GKM $_{\text {mod }}$ active site}

The L-cysteine inhibitor and water molecules were removed from the $1 \mathrm{GKM}_{\text {mod }}$ structure and a docking environment containing 29 amino acid residues [including His83, Arg283, Met382, Tyr53, Tyr280, Asn195 and Glu414 and MIO] was selected. For docking zwitterionic Lhistidine, Tyr53 and Tyr280 were kept deprotonated and four torsion angles (along the axes of $\mathrm{C}_{5}-\mathrm{C}_{\beta}, \mathrm{C}_{\beta}-\mathrm{C}_{\alpha}, \mathrm{C}_{\alpha}-\mathrm{N}$ and $\left.\mathrm{C}_{\alpha}-\mathrm{C}_{\mathrm{COO}^{-}}\right)$were varied, whereas for docking (E)-urocanate, protonated forms of Tyr53 and Tyr280 were used. Gasteiger charges were added to the atoms of the binding interfaces used for docking by AutoDock $[49,50]$. During the docking with AutoDock [49, 50], the zwitterionic L-histidine and $(E)$-urocanate were flexible in a rigid enzymic environment. The Grid Parameter File was established with the default settings (Total Grid Pts per map: 77326; number of points 40 for $\mathrm{x}$ - and y-dimensions, 45 for $\mathrm{z}$ dimension; spacing: $0.375 \AA$; center on ligand) and docking processes were also run with the default settings (Lamarckian Genetic Algorithm: 10 runs; population size: 150; maximum number of energy evaluations: short setting). 


\section{DFT calculations on ligands involved in HAL reactions}

DFT calculations were carried out on L-histidine and L-4-nitrohistidine models (both with protonated amino groups) for conformations corresponding to the HAL bound state, on a truncated model of the $N$-MIO-intermediate (by replacing the MIO ring of the calculated structure with a hydrogen atom at the exocyclic methylene carbon of MIO) and on a partial active site model including the truncated model of the $N$-MIO-intermediate in coordination with a $\mathrm{Zn}^{2+}$ ion, which is also coordinated to representative parts of His83 and Met382 and to a water. The DFT optimizations were performed using the GAUSSIAN 09 (rev. A.1) [51] and GaussView [52] as front-end. Two positively charged L-histidine structures (with - $\mathrm{COOH}$ and $-\mathrm{NH}_{3}{ }^{+}$) were constructed from the $N-\mathrm{MIO}$ models (from conformations $\mathrm{c} 5$ and $\mathrm{c} 4$ of the $\mathrm{N}_{\tau \mathrm{H}}$ and $\mathrm{N}_{\pi \mathrm{H}}$ series of CSs, respectively). Two positively charged L-nitrohistidine models were built from these two L-histidine structures by replacing the hydrogen at $\mathrm{C}_{4}$ of the imidazole with a nitro group.

In the $\mathrm{Zn}^{2+}$ complex models, the $\mathrm{Zn}^{2+}$ ion had four or five ligands: the imidazole of the $N-\mathrm{MIO}\left(\mathrm{N}_{\pi \mathrm{H}}\right)$ ligand at the $N_{\tau}$-atom (i.e. the 44 conformer of the $N-\mathrm{MIO} \mathrm{N}_{\pi \mathrm{H}}$ series, with a $\mathrm{NH}_{2}\left(\mathrm{CH}_{3}\right)^{+}$group as a model of the amino moiety bound to MIO, truncated between the MIO ring and the exocyclic carbon), a 4-methyl-1H-imidazole (coordinated at $N_{\tau}$, representing His83), a dimethyl sulfide (coordinated at its S-atom, representing Met382) and one (in the tetrahedral case) or two (in the trigonal bipyramidal case) water molecules. Proper constraints were used to maintain the conformation of the MIO-bound histidine ligand (HisL) as allowed within the HAL active site. For the $\mathrm{Zn}^{2+}$ complex models, several atomic positions were frozen [in Model 1: an oxygen atom of carboxylic acid moiety of the MIO-bound histidine ligand (the one which was closer to Arg283), the carbon atom of the methyl group of 4methylimidazole (truncated His83); in Model 2: as in Model $1+$ a carbon atom of the dimethyl sulfide (representing the $\mathrm{C}_{\gamma}$ atom of Met382); in Model 3: as in Model $1+$ methylene carbon atom of MIO; and in Model 4: as in Model $1+$ a carbon atom of the dimethyl sulfide (representing the $\mathrm{C}_{\gamma}$ atom of Met382) and methylene carbon atom of MIO].

Full geometry optimizations for the two types of L-histidine, L-4-nitrohistidine and the tetrahedral or trigonal bipyramidal $\mathrm{Zn}^{2+}$ complexes were carried out by the DFT method using Becke's three parameter hybrid functional combined with the Lee-Yang-Parr correlation functional (B3LYP) [53, 54], with the 6-31G or 6-31G(d,p) basis sets. After optimizations, vibrational frequencies were computed at the same level of theory and single point energies were calculated with a larger basis $\left[6-311+\mathrm{G}(\mathrm{d}, \mathrm{p})\right.$ for $\mathrm{Zn}^{2+}$, for the two imidazole rings, for 
the $-\mathrm{S}-\mathrm{CH}_{3}$ part of Met382 and for the water molecule(s); and 6-31G(d) for the other parts of the $\mathrm{Zn}^{2+}$ complex models].

\section{Results and discussion}

Unfortunately, the available X-ray structures of HAL do not contain substrate, product or $\mathrm{Zn}^{2+}$ ion $[16,19,37]$. This may be due to the partially open active site of the available HAL structures (Panel a in Fig. 4). Therefore, the goals of this study were to generate a proper HAL enzymic environment to investigate the alternative enzyme-bound reaction intermediates and the role of $\mathrm{Zn}^{2+}$ ion by means of computations.

\section{Construction of a closed HAL active site environment for calculations}

For modeling the closed active site containing state of HAL, the L-cysteine-inhibited PpHAL [37] was selected as a starting structure (PDB code: 1GKM). This is the only crystal structure of $P p H A L$ in which an inhibitor is present. Importantly, this is also the structure where the side chain of Met382 has a different conformation from the side chain arrangement of the other five unliganded $\mathrm{PpHAL}$ structures $[16,19]$.

Although the existing six PpHAL structures contain the Tyr53 inside the active site $[19,16$, 37], a structural comparison of HALs to the ammonia-lyases with tightly closed active sites indicated the Tyr-loops in all HAL structures are in a partially open conformation (Fig. 4a). The importance of the loop containing the catalytically essential tyrosine in the MIOcontaining ammonia-lyases was best demonstrated for PAL. The Tyr-loops were missing [14, $21,22]$ or were in catalytically inactive conformation [15, 55] in several crystal structures of PAL. Only recently, the structure of PAL from Anabaena variabilis (AvPAL) containing a tightly closed active site confirmed the active conformation of the Tyr-loop [13]. Similarly, the crystal structure of Rhodobacter sphaeroides tyrosine ammonia-lyase (RsTAL) revealed a tight active center in which the loop containing the essential Tyr60 was present in active conformation [23].

Comparison of the PpHAL (1GKM, in blue) structure to RsTAL (2O7B, in green) [23] and $A v$ PAL (3CZO, in orange and CPK color) [13] with compact active centers revealed that the catalytically essential Tyr53-containing loop of PpHAL adopts a partially open conformation 
(Fig. 4a). Because the most compact structure has been found for AvPAL (3CZO, $2.2 \AA$ resolution) containing the non-solvent accessible essential Tyr78 and the electrophilic MIO deeply buried in the active center [13], this ammonia-lyase structure has been selected as a template for modeling the compact conformation of the Tyr-loop of PpHAL.

Homology modeling was successful for modeling the essential Tyr-containing loop region of PAL (PcPAL, PDB code: 1W27 [15]) and thus in creating a proper active site environment for calculations inside PAL $[38,55]$. Therefore, a similar strategy was used to construct the compact active site of the PpHAL. A partially modified PpHAL crystal structure $\left(1 \mathrm{GKM}_{\text {mod }}\right)$ has been constructed by replacing the original 39-80 part (the partially open Tyr-loop) of every subunit of the L-cysteine inhibited PpHAL crystal structure (1GKM) with a closed HAL Tyr-loop model based on the closed Tyr-loop conformation of the AvPAL structure [13].

$<$ Figure 4>

Comparison of the Tyr53 containing inner loop region of the modified PpHAL $\left(1 \mathrm{GKM}_{\mathrm{mod}}\right.$, Fig. 4b, in red) to the Tyr-loop of the original L-cysteine inhibited PpHAL (1GKM, Fig. 4b, in blue) indicated that the catalytically essential Tyr53 in the modified structure was closer to $\mathrm{MIO}$, and therefore could better facilitate the pro-S $\beta$-proton elimination from the substrate, than in the original HAL structure. Moreover, Ramachandran-plot analysis of single subunits of the two HAL structures revealed that there were 8 amino acid residues outside the likely Phi/Psi combinations in the original HAL structure (1GKM, Fig. 4c), whereas there were only 4 unlikely combinations in the Tyr53-loop of the modified HAL structure $\left(1 \mathrm{GKM}_{\text {mod }}\right.$, Fig. $4 d)$.

Comparison of the conformation of the covalent reaction intermediates of the HAL reaction with the arrangements of the substrate and product

Some early reports have indicated that treatment of HAL at high $\mathrm{pH}$ in the presence of Lcysteine and oxygen leads to an irreversible inactivation of the enzyme [56, 57]. On denaturation, the L-cysteine inhibited HAL, followed by pronase digestion resulted in two main chromophoric products [58]. In one product, the exocyclic methylene of the MIO was substituted by the amino groups of L-cysteine. When L-cysteine inhibited HAL was first digested with trypsin, two chromophoric 24-residue peptides were isolated and identified as $N-\mathrm{MIO}$ fragments [59]. This was later supported by the L-cysteine inhibited structure of 
PpHAL (PDB code: 1GKM) [37]. The inhibited HAL contains the inhibitor with its amino moiety close to the exocyclic methylene of the electrophilic MIO prosthetic group. This fact can be considered as a further proof for the presence of an amino-enzyme intermediate in the HAL reaction demonstrated by Peterkofsky [60].

Structures of the HAL with L-cysteine [37], TAL with 2-aminoindan-2-phosphonate inhibitor [23] and TAM co-crystallized with $\alpha, \alpha$-difluoro- $\beta$-tyrosine [61] or $p$-fluorocinnamate epoxide [62] provided strong evidence for reactions via $\mathrm{N}-\mathrm{MIO}$ intermediates (in which the substrate is connected to MIO through its amino group) for the ammonia-lyase and aminomutase reactions. An alternative covalently bound intermediate was proposed by Rétey and coworkers [32]. In this case, a $\sigma$-complex would be formed between the aromatic part of the substrate and the MIO prosthetic group by Friedel-Crafts-like mechanism (FC).

Analysis of the active site residues surrounding the ligand in the L-cysteine-inhibited HAL [37] indicated that the pro-S $\beta$-proton from the L-histidine substrate can be abstracted by one of the three residues (Tyr53, Tyr280, Glu414) which might be considered as enzymatic bases (Fig. 5). Mutagenesis experiments also demonstrated that Tyr53, Glu414 [33], and Tyr 280 $[33,37]$ are important residues for the catalysis. The remarkably reduced catalytic activity of the analogous tyrosine (Tyr 60 and Tyr300) mutants of TAL [63] implies the importance of Tyr53 and Tyr280 in the HAL reaction.

When PAL was investigated with the phenylalanine analogues D- and L-2-aminooxy-3phenyl-propionic acid, it was deduced that ammonia elimination approximated the leastmotion course [64]. In several RsTAL structures, products of the elimination reaction were found in the active site in a zig-zag orientation [23]. The least-motion course principle and the similar straight chain zig-zag shape of the $(E)$-urocanate product of the HAL reaction determine a straight chain zig-zag arrangement of the covalently bound intermediate and the L-histidine substrate as well. Irrespectively of the nature of the covalently bound reaction intermediate, four reaction paths can fulfill these requirements (Fig. 5).

$<$ Figure 5>

Along the A-1 reaction path for transformation of the substrate to product, both $N-\mathrm{MIO}$ and FC intermediates are possible but only the Tyr53 amino acid could abstract the pro-S $\beta$-proton from the substrate. Only an FC-like mechanism is possible via the A-2 path involving Tyr280 
as the base for pro-S $\beta$-proton abstraction. Along the B-1 path, deamination of L-histidine may take place by the FC mechanism involving Glu414 as an enzymic base. Along the B-2 path, both types of the mechanism ( $N-\mathrm{MIO}$ and FC) can be taken into account involving Tyr53 as the base for abstraction of the pro-S $\beta$-proton.

In addition to the substrate and product states (Fig. 5), the covalently bound reaction intermediate should also fulfill the requirements of least-motion course in the HAL active site. If the HAL reaction proceeded via the $N-\mathrm{MIO}$ intermediate, the amino moiety of the Lhistidine substrate would be bound to MIO. If the HAL reaction proceeded via a FriedelCrafts type intermediate, the $\mathrm{C}_{4}$ carbon of the aromatic ring of L-histidine substrate would form a $\sigma$-complex with MIO. However, in this case the reaction may take place via two diastereomeric intermediates $[(S, S)$-FC and $(R, S)$-FC] due to a newly forming center of asymmetry at the $\mathrm{C}_{4}$ carbon of the aromatic ring in the $\sigma$-complex.

As in cases of all possible intermediates the substrate was anchored to the enzyme by a covalent bond, the systematic conformational search (CS) with the alternative reaction intermediates was a powerful tool to find their possible arrangements within the HAL active site. Because none of the six HAL [16, 19, 37] crystal structures indicated significant variations at the most part of the active center, the CSs were performed in rigid enzyme environment. This approach was also supported by the analysis of the B-factors of the active site amino acid residues indicating low mobility (with exception of the residues of the mobile Tyr53-loop).

Because the imidazole ring allowed two different protonation states $\left(N_{\tau \mathrm{H}}\right.$ or $\left.N_{\pi \mathrm{H}}\right)$ for each reaction intermediates, six CSs were performed for the three principal alternatives $[N$-MIO$N_{\tau \mathrm{H}}, \quad N-\mathrm{MIO}-N_{\pi \mathrm{H}}, \quad(R, S)$-FC- $N_{\tau \mathrm{H}}, \quad(R, S)$-FC- $N_{\pi \mathrm{H}}, \quad(S, S)$-FC- $N_{\tau \mathrm{H}}, \quad(S, S)$-FC- $\left.N_{\pi \mathrm{H}}\right] . \quad$ Only those conformations were kept which had a straight chain zig-zag arrangement within the lowest 10 $\mathrm{kcal} \mathrm{mol}^{-1}$ range (Table 1). From the retained conformations of the covalent intermediates of the six CSs, L-histidine and $(E)$-urocanate containing active site models were constructed. The substrate and product and the surrounding eight catalytically relevant amino acid residues were optimized within the closed HAL $\left(1 \mathrm{GKM}_{\text {mod }}\right)$ active site. In this way, comparative analysis of the full $\mathrm{S} \rightarrow \mathrm{I} \rightarrow \mathrm{P}\left(+\mathrm{NH}_{2}\right)$ reaction pathways become feasible (Table 1).

Although the energies obtained at the MM level of theory are usually not accurate enough for reliable enzyme mechanistic studies, several observations are worth mentioning. According to our calculations (Table 1), energetic results also favor the reaction via $N-\mathrm{MIO}\left(N_{\tau \mathrm{H}}\right)$ type 
intermediates (especially via the c5 and c8 conformations). In the $N-\mathrm{MIO}\left(N_{\tau \mathrm{H}}\right)$ case, the substrate binding states are of substantially higher energy than the corresponding reactive $N$-MIO type intermediates and the product binding states are of the lowest energies. As in all cases of the $N-\mathrm{MIO}\left(N_{\tau \mathrm{H}}\right)$ type route the energy of the substrate biding state is substantially higher than the energy of the corresponding product biding state, the calculated energy profile of the reaction is in full agreement with experimental results since MIO-containing ammonialyases catalyze, under normal conditions, ammonia elimination from the L-amino acids in a practically irreversible manner [1, 18]. Although the other types of intermediates can be disclosed as reactive species by non-energetic arguments discussed later, it is worth to note thet all the other intermediate structures had higher energies $\left(10.8-33.1 \mathrm{kcal} \mathrm{mol}^{-1}\right)$ than the lowest energy $N-\mathrm{MIO}\left(N_{\tau \mathrm{H}}\right)$ intermediate conformer.

Next, the H-O distances in the optimized structures of the MIO-bound intermediate models between the ligand's pro-S $\beta$-hydrogen and oxygen atoms of the possible enzymic bases (Tyr53, Tyr280 and Glu414) and between ligand's carboxylate oxygen group and Arg283 were analyzed (Table 1). The most decisive result of this analysis was the observation that there was no enzymic base in any of the FC-intermediate conformations which was close enough to the pro-S $\beta$-hydrogen to abstract it. Therefore, the A-1 pathway involving an $N$-MIO covalent intermediate is the most plausible for the HAL reaction but a B-2 type orientation would also be allowed.

$<$ Table 1>

The optimized structures containing L-histidine and $(E)$-urocanate ligands in the active site of the closed HAL structure were compared to the arrangements of these ligands obtained by a docking procedure. The analysis of the AutoDock results revealed a well conserved orientation of the product (the carboxylate of the ligand is in the vicinity of the Arg 283 while the imidazole moiety points towards His83) and agreed with the results obtained from the MM optimizations. Taking into account the orientation of the product within the active site, the docking results corresponded only to the A-1 pathway.

\section{The role of $\mathrm{Zn}(\mathrm{II})$ in the $\mathrm{HAL}$ reaction}

The first known zinc-containing enzyme, carbonic anhydrase, was discovered in 1932 and was found to contain bound zinc, associated with catalytic activity [65, 66]. Nowadays, many 
enzymes are known to contain zinc coordinated to two or three histidine residues and to other residues or water molecules [67-69]. Enzymes may contain two histidines both coordinating the $\mathrm{Zn}$ ion by their $N_{\pi}$ atoms $[70,71]$ or at their $N_{\tau}$ atoms [1], or in some cases the $\mathrm{Zn}$ ion is coordinated by one His at $N_{\pi}$, whereas by the other His at $N_{\tau}[70,72-74]$.

It was observed that $\mathrm{Zn}^{2+}$ or a number of different divalent cations, like $\mathrm{Cd}^{2+}$ or $\mathrm{Mn}^{2+}$, increase the activity of HAL [35]. On the other hand, there is no $\mathrm{Zn}^{2+}$ containing crystal structure for HAL $[16,19,37]$. This apparent contradiction can be resolved by assuming that $\mathrm{Zn}^{2+}$, which is necessary for the catalytic activity, interacts during the HAL reaction with the HAL-specific His83 residue and with the imidazole of the substrate [33]. Therefore, the reason why no $\mathrm{Zn}^{2+}$ containing $\mathrm{HAL}$ structure is known is that no substrate or product containing HAL structure has been determined so far $[16,19,37]$. Interaction of a $\mathrm{Zn}^{2+}$ with the HAL-specific His83 and with the substrate during the catalysis [33] can also rationalize why HAL accepts only L-histidine [1], L-4-fluorohistidine [75] or L-4-nitrohistidine [32, 76] as substrates.

\section{$<$ Figure 6>}

To examine the contribution of the $\mathrm{Zn}^{2+}$ in HAL, model studies were performed on the conformations found for the $N-\mathrm{MIO}$ intermediate in the $1 \mathrm{GKM}_{\text {mod }}$ active site. Analysis of the existing Zn-containing protein crystal structures [70-74] and the calculated $N-\mathrm{MIO}$ intermediate conformations led to the conclusion that $\mathrm{Zn}$ could be coordinated at $N_{\tau}$ atoms of His83 and of the substrate's imidazole (Fig. 6a), similarly as found in Adamalysin II, a zinc endopeptidase from the snake venom of Crotalus adamanteus [77] (Fig. 6b).

In the $\mathrm{Zn}$-containing protein structures, two kinds of $\mathrm{Zn}$-complexes can be found [73, 74]. The $\mathrm{Zn}$ may be present in tetrahedral $(\mathrm{Th})[73,74]$ or trigonal bypiramidal $(\mathrm{Tbp})[70,71]$ complexes. During the HAL reaction, the further ligands of the $\mathrm{Zn}^{2+}$ coordinated to His 83 and to the imidazole of L-histidine can be the $\mathrm{S}$ atom of the Met382, which is a conserved residue of the histidine ammonia-lyases, and one (in a tetrahedral Zn-coordination, Th) or two water molecules (in a trigonal bipyramidal Zn-coordination, Tbp).

The DFT calculations were performed on the two kinds of truncated Zn-complex structures (Th and Tbp) including all important parts of the active site of HAL (partial elements of MIO, His83, Met382 and one or two conserved water molecules). The DFT calculations indicated 
that the reaction of HAL should include a tetrahedral Zn-complex, because only tetrahedral complexes resulted in reasonable structures (Table 2). Optimizations of all possible kinds of trigonal bipyramidal Zn-complex arrangements aborted or led to tetrahedral structures by exclusion of a water. Comparison of the tetrahedral $\mathrm{Zn}$-complex (Fig. 6c) with the $\mathrm{Zn}^{2+}$ complex found in Adamalysin II [77] (Fig. 6b) and with the possible arrangement of the substrate-MIO covalent intermediate obtained by conformational analysis in the Zn-free active site (Fig. 6a) indicated good agreement in the spatial arrangement of the structures.

$<$ Table 2>

The overlay of the truncated tetrahedral $\mathrm{Zn}$-complex and the ligand-free HAL structure (Fig. 6c) indicated that $N_{\tau}$ atom of the ligand's imidazole was involved in the $\mathrm{Zn}$ coordination, whereas the hydrogen atom on the $N_{\pi}$ position could be at H-bond distance from Glu414 (Fig. 6a and Fig. 6c). The binding of the ligand during the HAL reaction at its imidazole ring by His83 via the Zn-complex and by Glu414 via a hydrogen bond is in full agreement with active site mutation data indicating that the Glu414Ala $\left(k_{\text {cat }} / k_{\text {cat-mut }}=20930\right)$ and the His83Leu $\left(k_{\text {cat }} / k_{\text {cat-mut }}=18000\right)$ mutations have the most dramatic effect on catalysis [33]. Although it might be considered that zinc(II) activates the enzyme by other mechanism, this mode of substrate binding can rationalize the very narrow substrate specificity (in addition to Lhistidine, only L-4-fluorohistidine [75] and L-4-nitrohistidine [32, 76] are accepted as substrates [1]) of HAL as well.

All the previous results implied that the enzymic base in the HAL reaction which abstracts the pro- $S \beta$-hydrogen as a proton is Tyr53. This was indicated by the $1.99 \AA$ distance between the oxygen atom of Tyr53 and the pro-S $\beta$-hydrogen of the tetrahedral $\mathrm{Zn}$-complex as well (Fig. $6 c)$.

Although Mulliken charges cannot be used as clear arguments for the acidity of hydrogen atoms, analysis of Mulliken charges of the pro-S $\beta$-hydrogens of L-histidine, L-4-nitrohistidine and truncated models for the $\mathrm{Zn}$-free and $\mathrm{Zn}$-coordinating $N$-MIO intermediates in the conformations allowed in the closed active site of HAL was performed (Table 3). L-4Nitrohistidine was also included because it is known that the nitro group acidifies the pro-S $\beta$ hydrogen of L-4-nitrohistidine [76] and it is accepted as substrate even by the MIO-less mutant of HAL 32]. The Mulliken charges found for pro-S $\beta$-hydrogen at the optimized geometries of L-histidine, L-4-nitrohistidine ( $N_{\tau \mathrm{H}}$ forms) and the Zn-complex models (Table 3 ) indicated that the pro-S $\beta$-hydrogen was significantly more polarized in L-4-nitrohistidine 
(Entry 3) than in the L-histidine (Entry 2) or in the Zn-free $N$-MIO model (Entry 1). The most charged pro-S $\beta$-hydrogens, however, were found in the Zn-complex models (Entries 4-7).

$<$ Table 3>

These results imply that the formation of a transient Zn-complex in the HAL reaction contributes not only to the specific binding of the substrate but to the enhancement of its reactivity as well. Further details of the HAL reaction and the $\mathrm{Zn}$-complex will be studied on a QM/MM model of the full active site of HAL in the near future.

\section{Conclusions}

The present study revealed that the existing experimental structures of histidine ammonialyase from Pseudomonas putida (PpHAL) contain an essential Tyr53-containing loop in a partially opened conformation. The modified, closed HAL structure (constructed by modeling the 39-80 loop with the catalytically essential Tyr53 on the basis of AvPAL) resulted less deviations from the allowed side chain conformations in the Ramachandran-plot than the original experimental structure.

Investigation of distances between the acidic pro-S $\beta$-hydrogen at $\mathrm{C}_{2}$ of ligand and the appropriate oxygen atoms of the possible enzymic bases Tyr53, Ty280 and Glu414 in the calculated conformations of the three proposed structures $[N-\mathrm{MIO},(R, S)-\mathrm{FC},(S, S)$-FC] of the covalently bound reaction intermediate within the closed active site of HAL revealed that the reaction can only take place via the $N$-MIO intermediate structure which allowed Tyr53 to get close enough to the pro-S $\beta$-hydrogen. This conclusion was also supported by the docking results with $(E)$-urocanate.

DFT calculations on the role of a $\mathrm{Zn}^{2+}$ ion in the HAL reaction using a truncated model of the $N$-MIO intermediate indicated the formation of a tetrahedral complex with a $\mathrm{Zn}^{2+}$ ion coordinated to the imidazole ring of the ligand, to His83 and Met382 residues of the enzyme and to a water molecule. The formation of such transient $\mathrm{Zn}$-complex could explain the narrow substrate specificity of HAL. The DFT calculations indicated also that the formation of a $\mathrm{Zn}$-complex had a contribution to the enhancement of the pro-S $\beta$-hydrogen's reactivity in the $N$-MIO intermediate as well. 


\section{Acknowledgments}

$A L S$ thanks the financial support of Romanian National University Research Council (CNCSIS, PNII-TD-400). PL thanks the financial support by the Hungarian National Science Foundation (OTKA T-048854) and by the Hungarian National Office for Research and Technology (NKTH A2 2007 FLOWREAC). 


\section{References}

1. Poppe L, Rétey J (2005) Friedel-Crafts type mechanism for the enzymatic elimination of ammonia from histidine and phenylalanine. Angew Chem Int Ed 44:3668-3688. doi: 10.1002/anie.200461377

2. Morrison H, Bernasconi C, Pandey G (1984) A wavelength effect on urocanic acid E/Z photoisomerization. Photochem Photobiol 40:549-550. doi: 10.1111/j.17511097.1984.tb04632.x

3. Taylor RG, Levy HL, McInnes RR (1991) Histidase and histidinemia. Clinical and molecular considerations. Mol Biol Med 8:101-116. PMID: 1943682

4. Consevage MW, Phillips AT (1985) Presence and quantity of dehydroalanine in histidine ammonia-lyase from Pseudomonas putida. Biochemistry 24:301-308. doi: 10.1021/bi00323a010

5. Fessenmeier M, Frank R, Schubert C, Rétey J (1991) Cloning and sequencing the urocanase gene (hutU) from Pseudomonas putida. FEBS Lett 286:55-57. doi: 10.1016/0014-5793(91)80938-Y

6. Taylor RG, Garcia-Heras J, Sadler SJ, Lafreniere RG, Willard HF, Ledbetter DH, McInnes RR (1991) Localization of histidase to human chromosome region $12 \mathrm{q} 22 \rightarrow \mathrm{q} 24.1$ and mouse chromosome region $10 \mathrm{C} 2 \rightarrow \mathrm{D} 1$. Cytogenet Cell Genet 56:178181. doi: $10.1159 / 000133082$

7. Taylor RG, Grieco D, Clarke GA, McInnes RR, Taylor BA (1993) Identification of the mutation in murine histidinemia (his) and genetic mapping of the murine histidase Locus (Hal) on chromosome 10. Genomics 16:231-240. doi: 10.1006/geno.1993.1164

8. Taylor RG, McInnes RR (1994) Site-directed mutagenesis of conserved serines in rat histidase. J Biol Chem 269:27473-27477. PMID: 7961661

9. Emiliani G, Fondi M, Fani R, Gribaldo S (2009) A horizontal gene transfer at the origin of phenylpropanoid metabolism: a key adaptation of plants to land. Biology Direct. doi: $10.1186 / 1745-6150-4-7$

10. Hernandez D, Phillips AT (1993) Purification and characterization of Pseudomonas putida histidine ammonia-lyase expressed in Escherichia coli. Protein Express Purif 4:473-478. doi: 10.1006/prep.1993.1062

11. Taylor RG, Lambert MA, Sexsmith E, Sadler SJ, Ray PN, Mahuran DJ, McInnes RR (1990) Cloning and expression of rat histidase. Homology to two bacterial histidases and four phenylalanine ammonia-lyases. J Biol Chem 265:18192-18199. PMID: 2120224 
12. Oda M, Sugishita A, Furukawa K (1988) Cloning and nucleotide sequences of histidase and regulatory genes in the Bacillus subtilis hut operon and positive regulation of the operon. J Bacteriol 170:3199-3205. PMID: 2454913

13. Wang L, Gamez A, Archer H, Abola EE, Sarkissian CN, Fitzpatrick P, Wendt D, Zhang J, Vellard M, Bliesath J, Bell SM, Lemontt JF, Scriver CR, Stevens RC (2008) Structural and biochemical characterization of the therapeutic Anabaena variabilis phenylalanine ammonia-lyase. J Mol Biol 380:623-635. doi: 10.1016/j.jmb.2008.05.025

14. Calabrese JC, Jordan DB, Boodhoo A, Sariaslani S, Vanneli T (2004) Crystal structure of phenylalanine ammonia-lyase: multiple helix dipoles, implicated in catalysis. Biochemistry 43:11403-11416. doi: 10.1021/bi049053+

15. Ritter H, Schulz GE (2004) Structural basis for the entrance into the phenylpropanoid metabolism catalyzed by phenylalanine ammonia-lyase. Plant Cell 16:3426-3436. doi: $10.1105 /$ tpc. 104.025288

16. Schwede TF, Rétey J, Schulz GE (1999) Crystal structure of histidine ammonia-lyase revealing a novel polypeptide modification as the catalytic electrophile. Biochemistry 38:5355-5361. doi: 10.1021/bi982929q

17. Poppe L (2001) Methylidene-imidazolone: a novel electrophile for substrate activation. Curr Opin Chem Biol 5:512-524. doi: 10.1016/S1367-5931(00)00253-2

18. Rétey J (2003) Discovery and role of methylidene imidazolone, a highly electrophilic prosthetic group. Biochim Biophys Acta, Proteins Proteomics 1647:179-184. doi: 10.1016/S1570-9639(03)00091-8

19. Baedeker M, Schulz GE (2002) Autocatalytic peptide cyclization during chain folding of histidine ammonia-lyase. Structure 10:61-67. doi: 10.1016/S0969-2126(01)00692-X

20. Röther D, Merkel D, Rétey J (2000) Spectroscopic evidence for a 4-methylidene imidazol-5-one in histidine and phenylalanine ammonia-lyases. Angew Chem Int Ed 39:2462-2464 $\quad$ doi: $\quad 10.1002 / 1521-3773(20000717) 39: 14<2462:: A I D-$ ANIE2462>3.0.CO;2-H

21. Wang L, Gamez A, Sarkissian CN, Straub M, Patch MG, Han GW, Striepeke S, Fitzpatrick P, Scriver CR, Stevens RC (2005) Structure-based chemical modification strategy for enzyme replacement treatment of phenylketonuria. Mol Gen Metab 86:134140. doi: 10.1016/j.ymgme.2005.05.012

22. Moffitt MC, Louie GV, Bowman ME, Pence J, Noel JP, Moore BS (2007) Discovery of two cyanobacterial phenylalanine ammonia lyases: kinetic and structural characterization. Biochemistry 46:1004-1012. doi: 10.1021/bi061774g 
23. Louie GV, Bowman ME, Moffitt MC, Baiga TJ, Moore BS, Noel JP (2006) Structural determinants and modulation of substrate specificity in phenylalanine-tyrosine ammonialyases. Chem Biol 13:1327-1338. doi: 10.1016/j.chembiol.2006.11.011

24. Walker KD, Klettke K, Akiyama T, Croteau R (2004) Cloning, heterologous expression, and characterization of a phenylalanie aminomutase involved in taxol biosynthesis. J Biol Chem 279:53947-53954. PMID: 15494399

25. Steele CL, Chen Y, Dougherty BA, Li W, Hofstead S, Lam KS, Xing Z, Chiang SJ, (2005) Purification, cloning, and functional expression of phenylalanine aminomutase: the first committed step in taxol side-chain biosynthesis. Arch Biochem Biophys 438:110. doi: 10.1016/j.abb.2005.04.012

26. Mutatu W, Klettke KL, Foster C, Walker KD (2007) Unusual mechanism for an aminomutase rearrangement: Retention of configuration at the migration termini. Biochemistry 46:9785-9794. doi: 10.1021/bi700691p

27. Christenson SD, Liu W, Toney MD, Shen B (2003) A novel 4-methylideneimidazole-5one-containing tyrosien aminomutase in enediyne antitumor antibiotic C-1027 biosynthesis. J Am Chem Soc 125:6062-6063. doi: 10.1021/ja034609m

28. Christianson CV, Montavon TJ, Van Lanen SG, Shen B, Bruner SD (2007) The structure of 1-tyrosine 2,3-aminomutase from the C-1027 enediyne antitumor antibiotic biosynthetic pathway. Biochemistry 46:7205-7214. doi: 10.1021/bi7003685

29. Smith TA., Cordelle FH, Abeles RH (1967) Inactivation of histidine deaminase by carbonyl reagents. Arch Biochem Biophys 120:724-725. doi: 10.1016/00039861(67)90540-1

30. Hanson KR, Havir EA (1970) L-phenylalanine ammonia-lyase. IV. Evidence that the prosthetic group contains a dehydroalanyl residue and mechanism of action1. Arch. Biochem. Biophys. 141:1-17. doi: 10.1016/0003-9861(70)90100-1

31. Hermes J D, Weiss PM, Cleland WW (1985) Use of nitrogen-15 and deuterium isotope effects to determine the chemical mechanism of phenylalanine ammonia-lyase. Biochemistry 24:2959-2967. doi: 10.1021/bi00333a023

32. Langer M., Pauling A., Rétey J (1995) The role of dehydroalanine in catalysis by histidine ammonia-lyase. Angew Chem Int Ed 34:1464-1465. doi: 10.1002/anie.199514641

33. Röther D, Poppe L, Viergutz S, Langer B, Rétey J (2001) Characterization of the active site of histidine ammonia-lyase from Pseudomonas putida. Eur J Biochem 268:60116019. doi: 10.1046/j.0014-2956.2001.02298.x 
34. Röther D, Poppe L, Morlock G, Viergutz S, Rétey J (2002) An active site homology model of phenylalanine ammonia-lyase from Petroselinum crispum. Eur J Biochem 269:3065-3075. doi: 10.1046/j.1432-1033.2002.02984.x

35. Klee CB (1972) Metal activation of histidine ammonia-lyase. Metal ion-sulfhydryl group relationship. J Biol Chem 247:1398-1406. PMID: 4622230

36. Givot IL, Smith TA, Abeles RA (1969) Studies on the mechanism of action and the structure of the electrophilic center of histidine ammonia lyase. J Biol Chem 244:63416353.PMID: 5354960

37. Baedeker M, Schulz GE (2002) Structures of two histidine ammonia-lyase modifications and implications for the catalytic mechanism. Eur J Biochem 269:1790-1797. doi: 10.1046/j.1432-1327.2002.02827.x

38. Seff AL, Pilbák S, Poppe L (2008) Ligand docking and systematic conformational analysis in loop modified parsley phenylalanine ammonia-lyase structure. Studia Universitatis Babes-Bolyai Chemia, LIII 53(2):67-71, ISSN 1224-7154

39. Bartsch S, Bornschauer UT (2009) A single residue influences the reaction mechanism of ammonia lyases and mutases. Angew Chem Int Ed 48:3362-3365. doi: 10.1002/anie.200900337

40. Swiss-PDBViewer version 4.0 (http://www.expasy.org/spdbv/)

41. Guex N, Peitsch MC (1997) SWISS-MODEL and the Swiss-Pdb Viewer: An environment for comparative protein modeling. Electrophoresis 18:2714-2723. doi: 10.1002/elps.1150181505

42. Schwede T, Kopp J, Guex N, Peitsch MC (2003) SWISS-MODEL: an automated protein homology-modeling server. Nucleic Acid Res. 31:3381-3385. doi: 10.1093/nar/gkg520

43. SWISS-MODEL (http://swissmodel.expasy.org/).

44. Arnold K, Bordoli L, Kopp J, Schwede T (2006) The SWISS-MODEL workspace: a web-based environment for protein structure homology modelling. Bioinformatics 22:195-201. doi: 10.1093/bioinformatics/bti770

45. Kopp J, Schwede T (2004) The SWISS-MODEL repository of annotated threedimensional protein structure homology models. Nucleic Acid Res. 32:D230-D234. doi: 10.1093/nar/gkh008

46. Peitsch MC (1995) Protein modelling by e-mail. Bio/Technology 13:658-660. doi: $10.1038 /$ nbt0795-658

47. HyperChem version 7.0 (Hypercube, Inc. http://www.hyper.com/)

48. Molfunction, Institute of Molecular Function (http://www.molfunction.com/)

49. Morris GM, Goodsell DS, Halliday RS, Huey R, Hart WE, Belew RK, Olson AJ (1998) Automated docking using a Lamarckian genetic algorithm and an empirical binding free 
energy function. J Comput Chem 19:1639-1662. doi: 10.1002/(SICI)1096987X(19981115)19:14<1639:: AID-JCC10>3.0.CO;2-B

50. Huey R, Morris GM, Olson AJ, Goodsell DS (2007) A semiempirical free energy force field with charge-based desolvation. J Comput Chem 28:1145-1152. doi: $10.1002 /$ jcc. 20634

51. Frisch MJ, Trucks GW, Schlegel HB, Scuseria GE, Robb MA, Cheeseman JR, Scalmani G, Barone V, Mennucci B, Petersson GA, Nakatsuji H, Caricato M, Li X, Hratchian HP, Izmaylov AF, Bloino J, Zheng G, Sonnenberg JL, Hada M, Ehara M, Toyota K, Fukuda R, Hasegawa J, Ishida M, Nakajima T, Honda Y, Kitao O, Nakai H, Vreven T, Montgomery Jr. JA, Peralta JE, Ogliaro F, Bearpark M, Heyd JJ, Brothers E, Kudin KN, Staroverov VN, Kobayashi R, Normand J, Raghavachari K, Rendell A, Burant JC, Iyengar SS, Tomasi J, Cossi M, Rega N, Millam NJ, Klene M, Knox JE, Cross JB, Bakken V, Adamo C, Jaramillo J, Gomperts R, Stratmann RE, Yazyev O, Austin AJ, Cammi R, Pomelli C, Ochterski JW, Martin RL, Morokuma K, Zakrzewski VG, Voth GA, Salvador P, Dannenberg JJ, Dapprich S, Daniels AD, Farkas Ö, Foresman JB, Ortiz JV, Cioslowski J, Fox DJ (2009) Gaussian 09, Revision A.1. Gaussian Inc, Wallingford CT

52. Dennington II R, Keith T, Millam J, Eppinnett K, Hovell WL Gilliland R (2003) GaussView, Version 3.09. Semichem Inc, Shawnee Mission, KS

53. Becke AD (1993) Density-functional thermochemistry. III. The role of exact exchange. J Chem Phys 98:5648-5652. doi: 10.1063/1.464913

54. Lee C, Yang W, Parr RG (1988) Development of the Colle-Salvetti correlation-energy formula into a functional of the electron density. Phys Rev B 37:785-789. doi: 10.1103/PhysRevB.37.785

55. Pilbák S, Tomin A, Rétey J, Poppe L (2006) The essential tyrosine-containing loop conformation and the role of the C-terminal multi-helix region in eukaryotic phenylalanine ammonia-lyases. FEBS J 273:1004-1019. doi: 10.1111/j.17424658.2006.05127.x

56- Klee CB (1974) Stereospecific irreversible inhibition of histidine ammonia-lyase by Lcysteine. Biochemistry 13:4501-4507. doi: 10.1021/bi00719a005

57. Hernandez D, Stroh JG, Phillips AT (1993) Identification of Ser $^{143}$ as the site of modification in the active site of histidine ammonia-lyase. Arch Biochem Biophys 307:126-132. doi: 10.1006/abbi.1993.1570

58. Merkel D, Rétey J (2000) Further insight into the mechanism of the irreversible inhibition of histidine ammonia-lyase by L-cysteine and dioxygen. Helv Chim Acta 83:1151-1160. doi: 10.1002/1522-2675(20000607)83:6<1151::AID-HLCA1151>3.0.CO;2-4 
59. Galpin JD, Ellis BE, Tanner ME (1999) The inactivation of histidine ammonia-lyase by L-cysteine and oxygen: modification of the electrophilic center. J Am Chem Soc 121:10840-10841. doi: 10.1021/ja992729h

60. Peterkofsky A (1962) The mechanism of action of histidase: Amino-enzyme formation and partial reactions. J Biol Chem 237:787-795. PMID: 14485719

61. Christianson CV, Montavon TJ, Festin GM, Cooke HA, Shen B, Bruner SD (2007) The mechanism of MIO-based aminomutases in $\beta$-amino acid biosynthesis. J Am Chem Soc 129:15744-15745. doi: 10.1021/ja0762689

62. Montavon TJ, Christianson CV, Festin GM, Shen B, Bruner SD (2008) Design and characterization of mechanism-based inhibitors for the tyrosine aminomutase SgTAM. Bioorg Med Chem Lett 18:3099-3102. doi: 10.1016/j.bmcl.2007.11.046

63. Schroeder AC, Kumaran S, Hicks LM, Cahoon RE, Halls C, Yu O, Jez JM (2008) Contribution of conserved serine and tyrosine residues to catalysis, ligand binding, and cofactor processing in the active site of tyrosine ammonia lyase. Phytochem 69:14961506. doi: 10.1016/j.phytochem.2008.02.007

64. Hanson KR (1981) Phenylalanine ammonia-lyase: mirror image packing of D- and Lphenylalanine and D- and L-transition state analogs into the active site. Arch Biochem Biophys 211:575-588. doi: 10.1016/0003-9861(81)90492-6

65. Meldrum NU, Roughton FJ (1933) Carbonic anhydrase. Its preparation and properties. J Physiol 80:113-142. PMID: 16994489

66. Berg JM, Tymoczko JL, Stryer L (2002) Biochemistry, $5^{\text {th }}$ Edn, Freeman WH, New York, NY, USA

67. Glusker JP (1991) Structural aspects of metal liganding to functional groups in proteins. Adv Protein Chem 42:1-76. PMID: 1793004

68. Rulísek L, Vondrásek J (1998) Coordination geometries of selected transition metal ions $\left(\mathrm{Co}^{2+}, \mathrm{Ni}^{2+}, \mathrm{Cu}^{2+}, \mathrm{Zn}^{2+}, \mathrm{Cd}^{2+}\right.$, and $\left.\mathrm{Hg}^{2+}\right)$ in metalloproteins. J Inorg Biochem 71:115-127. doi:10.1016/S0162-0134(98)10042-9

69. Zheng H, Chruszcz M, Lasota P, Lebioda L, Mino W (2008) Data mining of metal ion environments present in protein structures. J Inorg Biochem 102:1765-1776. doi:10.1016/j.jinorgbio.2008.05.006

70. Nauton L, Kahn R, Garau G, Hernandez JF, Dideberg O (2008) Structural insights into the design of inhibitors for the L1 metallo- $\beta$-lactamase from Stenotrophomonas maltophilia. J Mol Biol 375:257-269. doi: 10.1016/j.jmb.2007.10.036

71. Lipscomb WS, Strater N (1996) Recent advances in zinc enzymology. Chem Rev 96:2375-2433. doi: 10.1021/cr950042j 
72. Gerhardt S, Hassal G, Hawtin P, McCall E, Flavell E, Minshull C, Hargreaves D, Ting A, Pauptit RA, Parker AE, Abbott WM (2007) Crystal structures of human ADAMTS-1 reveal a conserved catalytic domain and a disintegrin-like domain with a fold homologouse to cysteine-rich domains. J Mol Biol 373:891-902. doi: 10.1016/j.jmb.2007.07.047

73. Bebrone C (2007) Metallo- $\beta$-lactamases (classification, activity, genetic organization, structure, zinc coordination) and their superfamily. Biochem Pharmacol 74:1686-1701. doi: 10.1016/j.bcp.2007.05.021

74. Debela M, Goettic P, Magdolen V, Huber R, Schechter NM, Bode W (2007) Structural basis of the zinc inhibition of human tissue Kallikrein 5. J Mol Biol 373:1017-1031. doi: 10.1016/j.jmb.2007.08.042

75. Klee CB, Kirk KL, Cohen LA, McPhie P (1975) Histidine ammonia-lyase. The use of 4fluorohistidine in identification of the rate determining step. J Biol Chem 250:5033-5040. PMID: 1150653

76. Klee CB, Kirk KL, Cohen LA (1979) 4-Nitro-L-histidine as a substrate for histidine ammonia-lyase: the role of beta-hydrogen acidity in the rate-limiting step. Biochem Biophys Res Commun 87:343-348. PMID: 36890

77. Gomis-Rüth FX, Kress LF, Bode W (1993) First structure of a snake venom metalloproteinase: a prototype for matrix metalloproteinases/collagenases. EMBO J 12:4151-4157. PMID: 8223430 


\section{Tables}

Table 1 MM relative energies of the models of substrate $\left(E_{S}\right)$, intermediate $\left(E_{I}\right)$ and product with MIO-bound amino group $\left(\mathrm{E}_{\mathrm{P}+\mathrm{NH} 2}\right)$ and representative $\mathrm{H}-\mathrm{O}$ distances in the covalent substrate-MIO intermediate structures

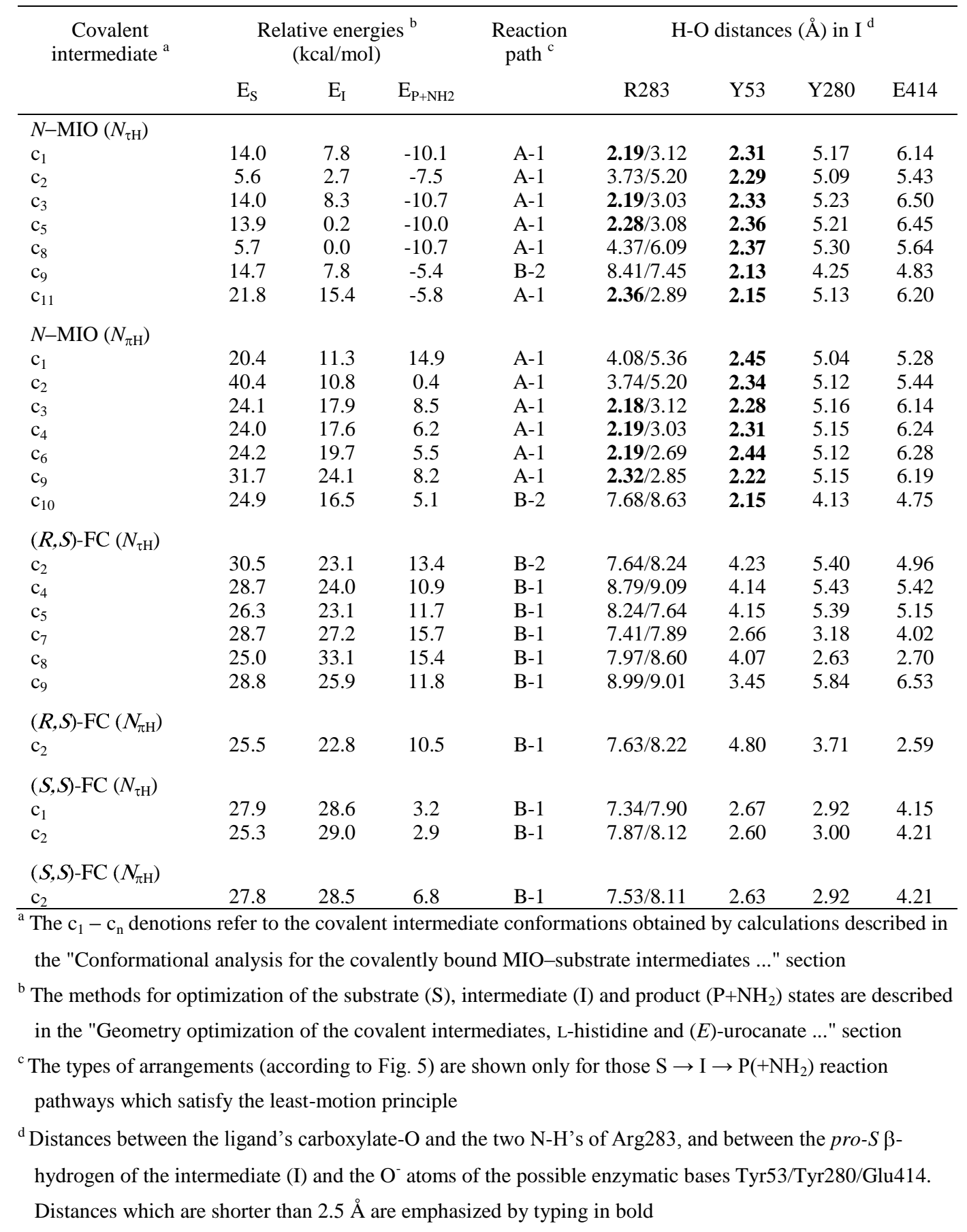


Table 2 Bond lengths and energies for tetrahedral zinc-ligand complex models calculated by

\section{DFT methods}

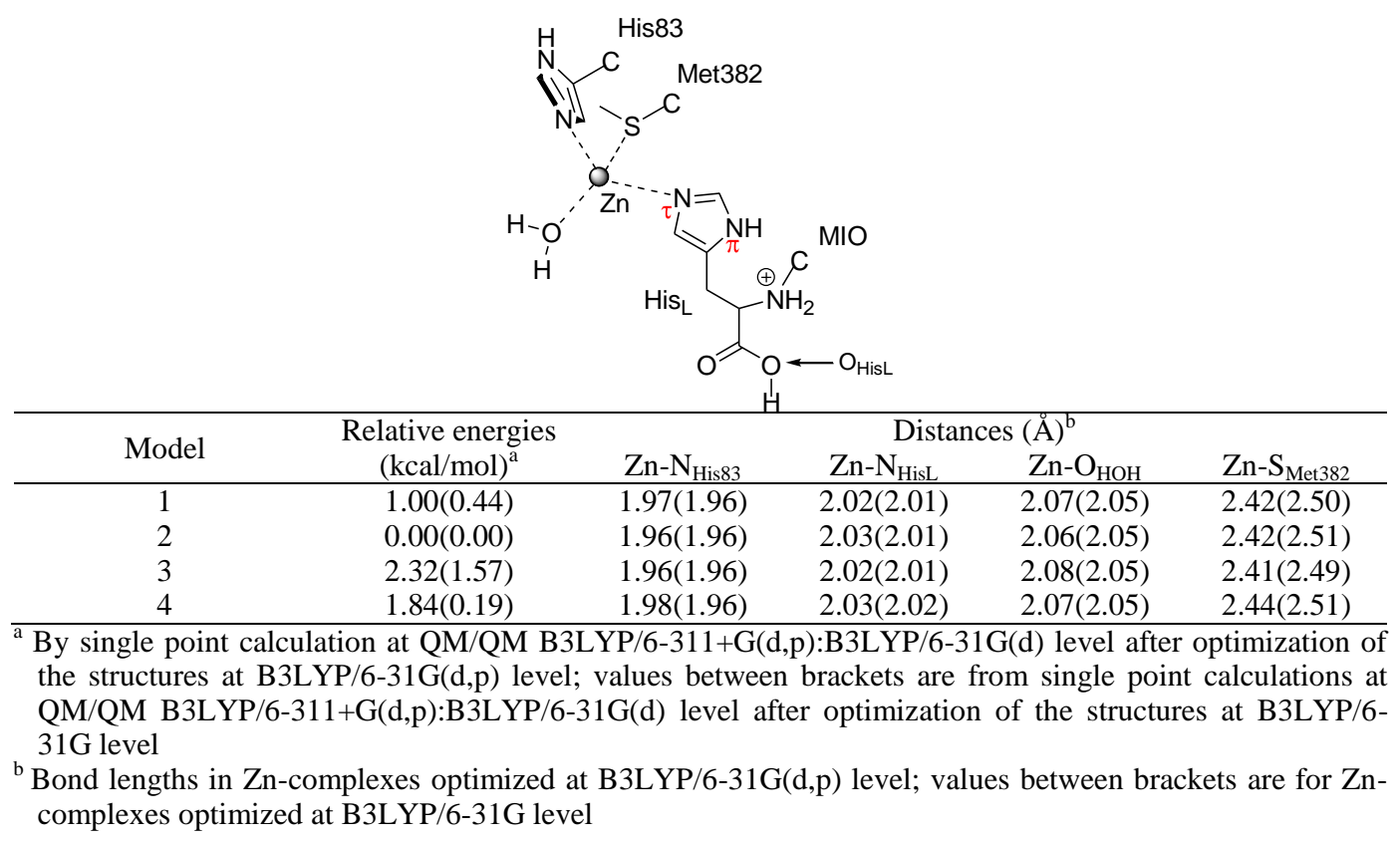


Table 3 Mulliken atomic charges of the pro-S $\beta$-hydrogens in zwitterionic L-histidine, in zwitterionic L-4-nitrohistidine, in a truncated $\mathrm{N}$-MIO-intermediate model and in the tetrahedral $\mathrm{Zn}$-complex models

\begin{tabular}{clcc}
\hline Entry & Structure $^{\mathrm{a}}$ & $\mathrm{H}_{S}$ & $\mathrm{H}_{R}$ \\
\hline 1 & N-MIO (TRUNCATED MODEL) & $0.176(0.221)$ & $0.133(0.173)$ \\
2 & L-Histidine & $0.180(0.222)$ & $0.102(0.166)$ \\
3 & L-4-Nitrohistidine & $0.199(0.245)$ & $0.135(0.201)$ \\
4 & Zn-complex, Model 1 & $0.220(0.267)$ & $0.172(0.206)$ \\
5 & Zn-complex, Model 2 & $0.220(0.265)$ & $0.173(0.208)$ \\
6 & Zn-complex, Model 3 & $0.220(0.263)$ & $0.174(0.208)$ \\
7 & Zn-complex, Model 4 & $0.215(0.261)$ & $0.177(0.210)$ \\
\hline
\end{tabular}

${ }^{a}$ Calculations on the ligand conformations allowed within the HAL active site were performed at B3LYP/6-31G $(\mathrm{d}, \mathrm{p})$ level (values between brackets are from B3LYP/6-31G DFT calculations) 


\section{Figure captions}

Fig. 1 The histidine ammonia-lyase (HAL) reaction with the proposed alternative reaction intermediates. [The nitrogens in the imidazole rings of L-histidine and $(E)$ urocanate are denoted according to IUPAC with pros ("near", $\pi$ ) and tele ("far", $\tau$ )]

Fig. 2 Proposed autocatalytic formation of MIO from the tripeptide Ala-Ser-Gly

Fig. 3 Construction of the L-histidine (colored in green) and (E)-urocanate (colored in blue) containing active site models from the $N$-MIO intermediate model of HAL

FIG. 4 The mobile Tyr-loops in the active site of MIO-containing ammonia-lyases. a. Comparison of two mobile regions (including the MIO stabilizing Asn and the catalytically essential Tyr residues) of four different ammonia-lyases: Anabaena variabilis PAL (3CZO, in orange and CPK color); Petroselinum crispum PAL (1W27, in bright green); Rhodobacter sphaeroides TAL (2O7B, in dark green); Pseudomonas putida HAL (1GKM, in blue). The Asn residue is numbered according to $A v$ PAL (3CZO). b. Overlay of the essential Tyr53 loop regions of PpHAL (1GKM inhibited with L-cysteine, colored by CPK, blue chain) and the Tyr-loop modified PpHAL (1GKM $\mathrm{God}_{\text {mod }}$, red chain). c. and d. Ramachandran plots for monomeric units of $P p H A L(1 G K M)$ and the partially modified $P p H A L$ $\left(1 \mathrm{GKM}_{\text {mod }}\right)$, respectively

Fig. 5 Four possible arrangements of L-histidine and $(E)$-urocanate along the reaction pathways (A-1, A-2, B-1 and B-2) assuming the least-motion course in the HAL active site containing the MIO prosthetic group, His83, Arg283 and three possible enzymatic bases: Tyr53, Tyr280 and Glu414

Fig. 6 a. Arrangement of the covalent $N$-MIO intermediate $\left(N_{\pi \mathrm{H}^{-}} \mathrm{c} 4\right)$ in the active site of HAL $\left(1 \mathrm{GKM}_{\mathrm{mod}}\right)$. b. The tetrahedral coordination of $\mathrm{Zn}$ (in pink) in the Adamalysin II, a zinc endopeptidase from the snake venom of Crotalus adamanteus [77] (PDB code: 1IAG). c. Fit of the tetrahedral Zn-complex model (Model 4, by DFT calculation) into the ligand-free active site of HAL $\left(1 \mathrm{GKM}_{\bmod }\right)$ 


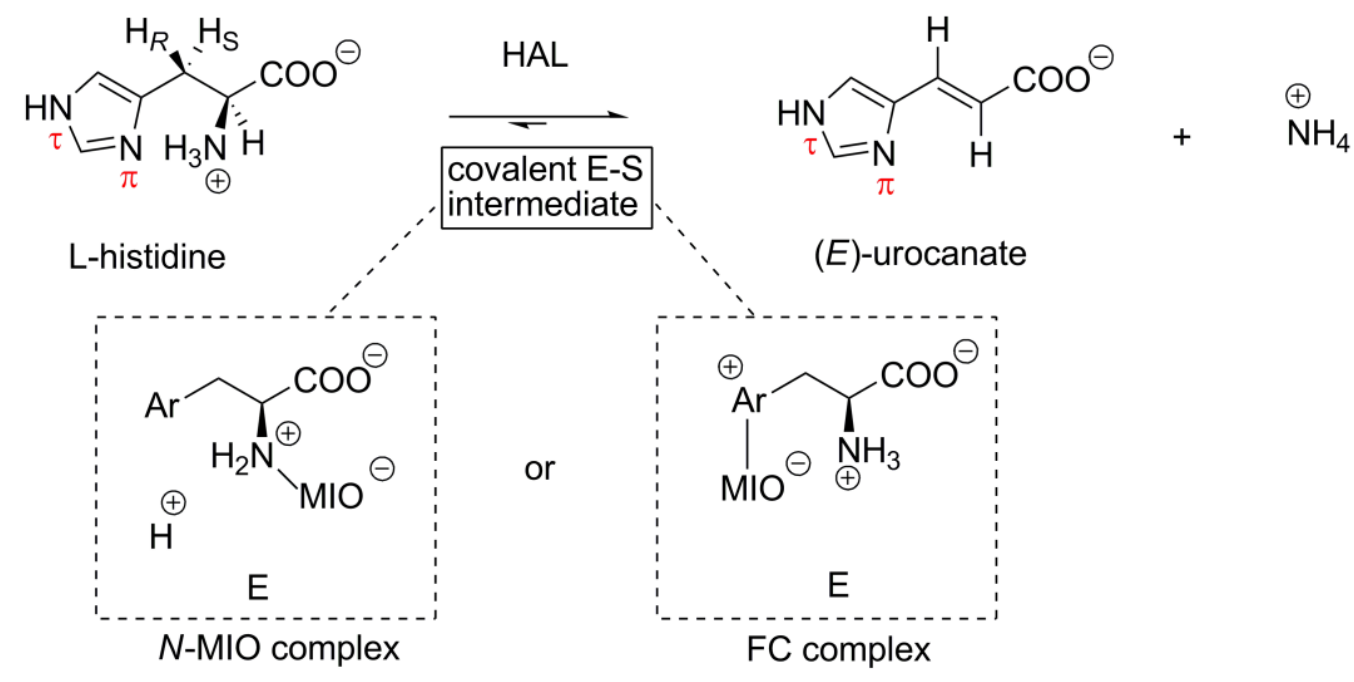



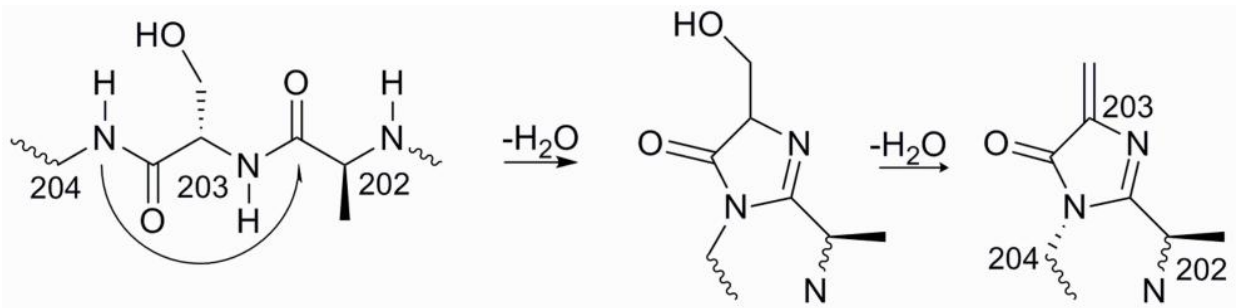

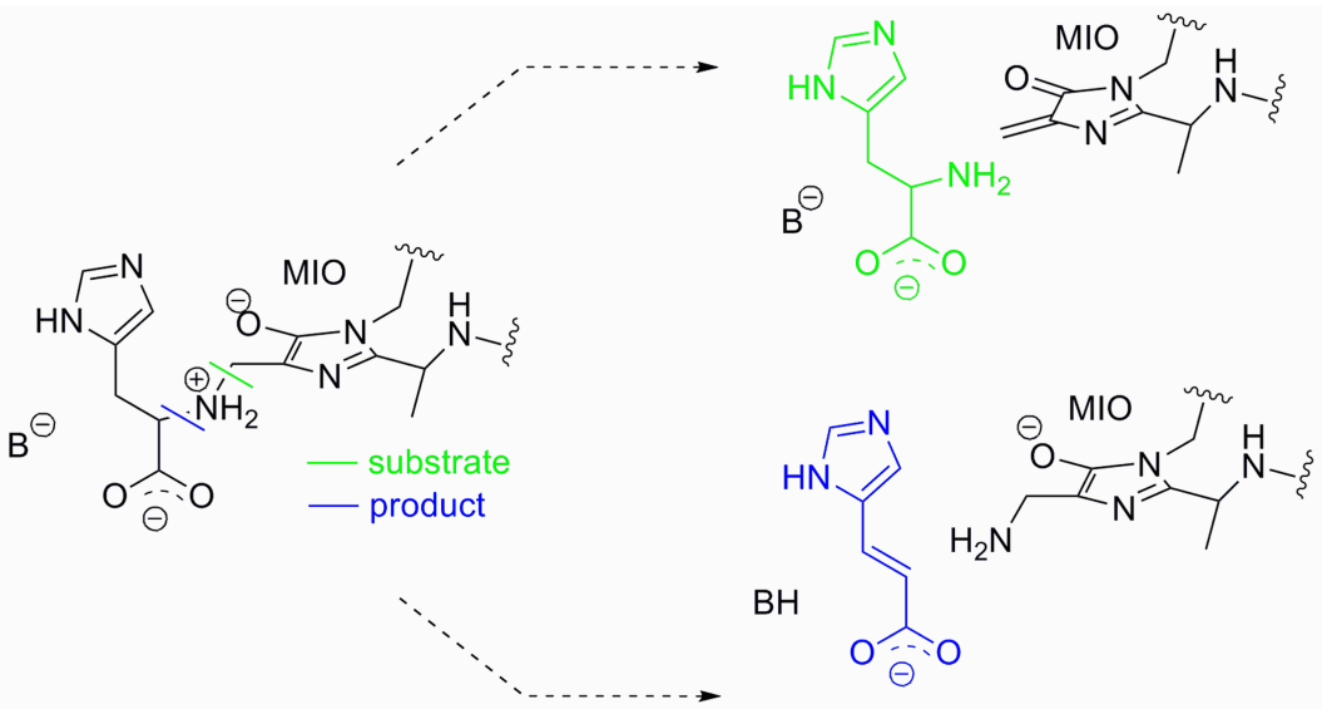

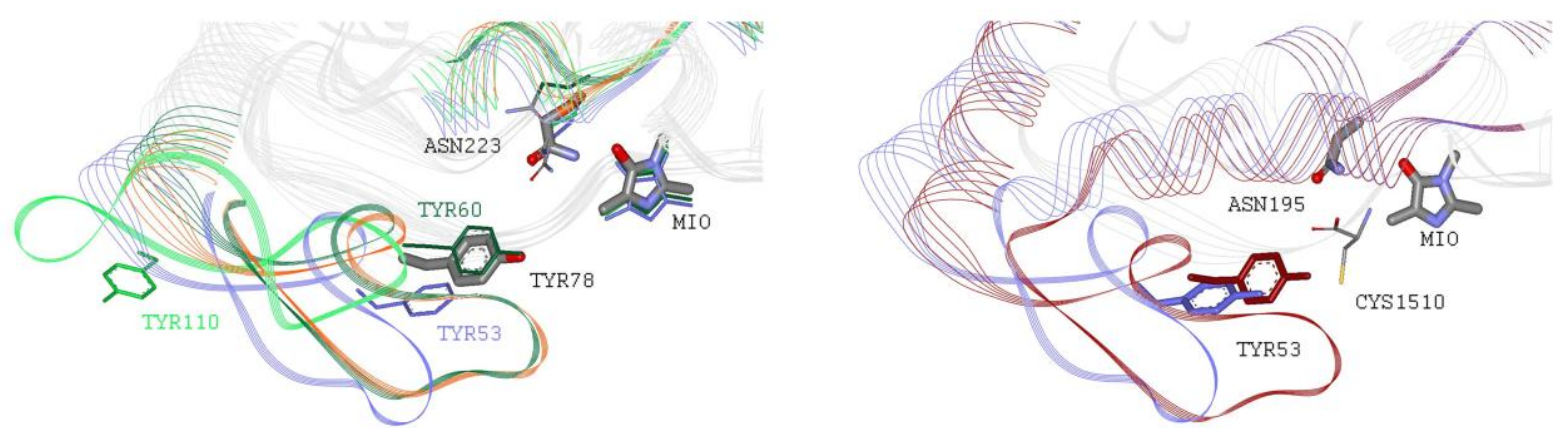

a

b
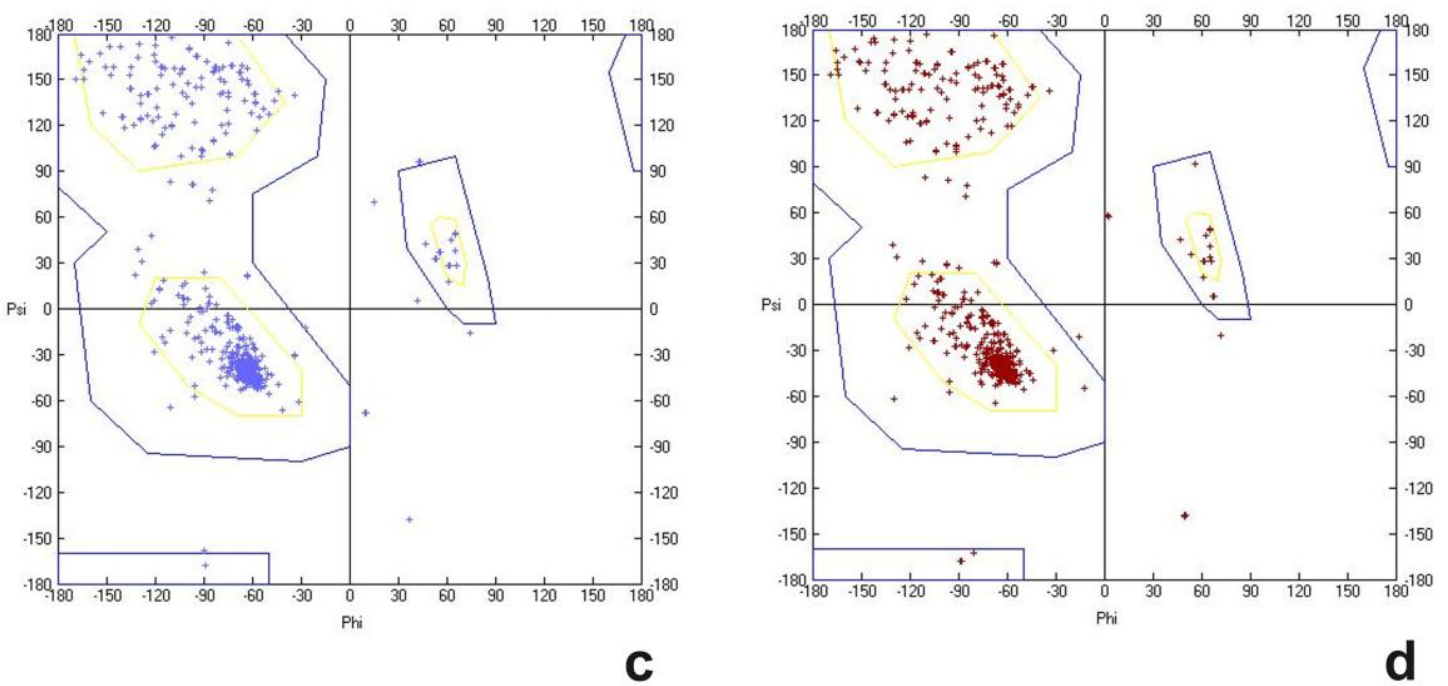

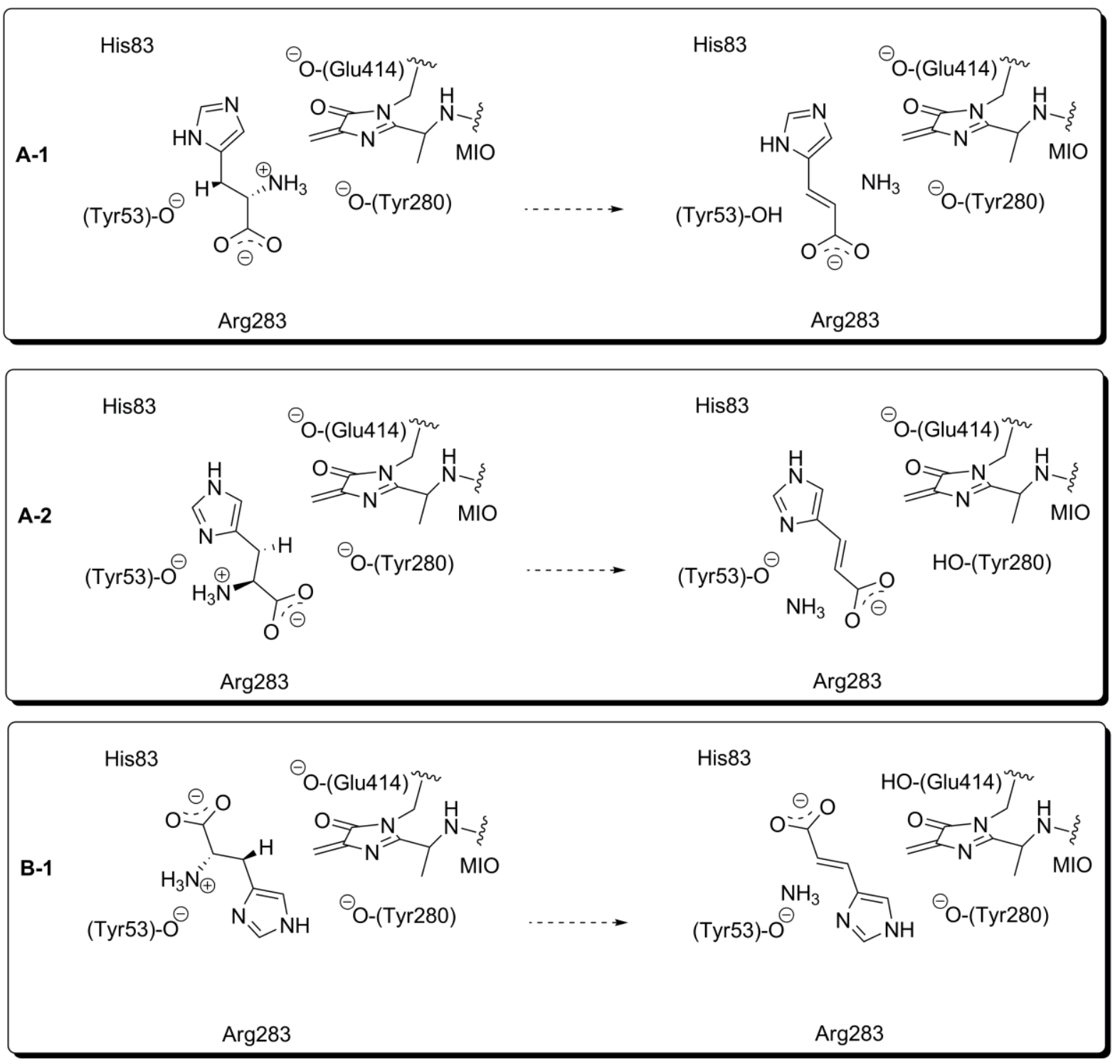

Arg283




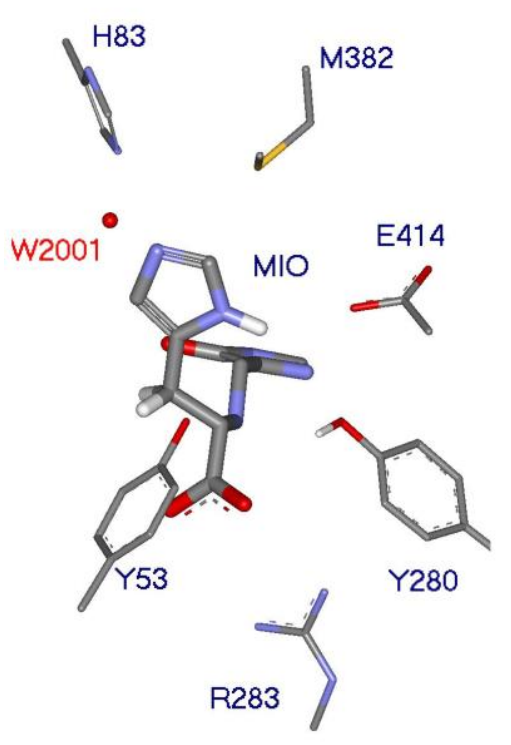

a

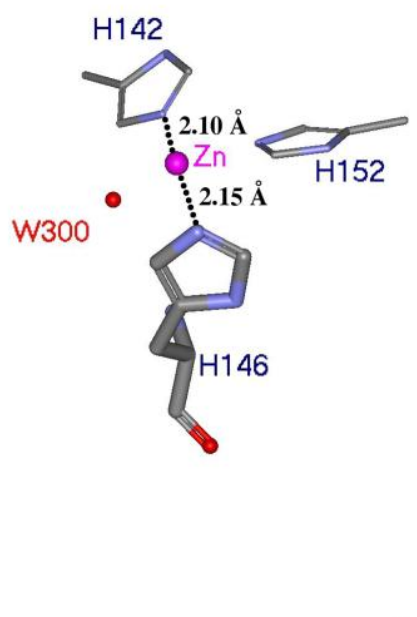

b

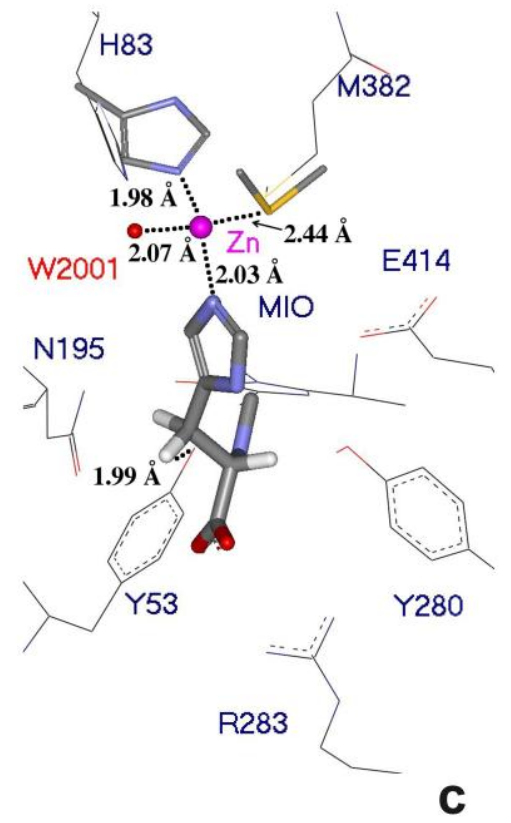




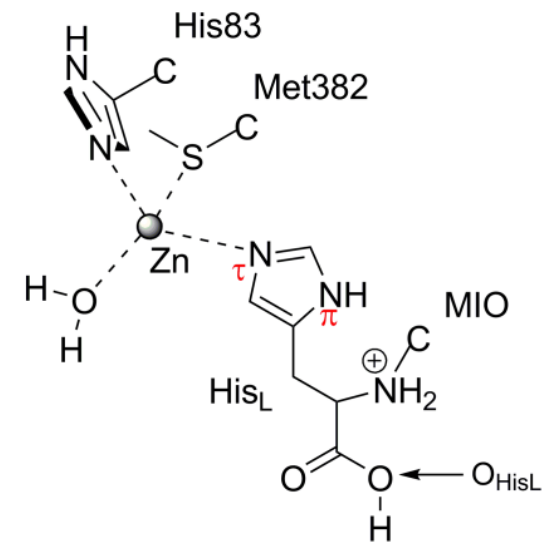

